EA 4272

\title{
Positive and negative preferences in human mate selection
}

\author{
Nicolas Vaillant $\left.{ }^{*}\right)$ \\ François-Charles Wolff $\left.{ }^{* *}\right)$
}

2010/09

$\left.{ }^{*}\right)$ LEM - Université Catholique de Lille

$\left.{ }^{* *}\right)$ LEMNA - Université de Nantes / CNAV - INED - Paris

Laboratoire d'Economie et de Management Nantes-Atlantique Université de Nantes

Chemin de la Censive du Tertre - BP 52231

44322 Nantes cedex 3 - France

www.univ-nantes.frliemn-iae/recherche 


\title{
Positive and negative preferences in human mate selection ${ }^{\#}$
}

\author{
Nicolas Gérard Vaillant ${ }^{*} \quad$ François-Charles Wolff ${ }^{* *}$
}

January 2010

\begin{abstract}
This paper focuses on preferences for specific characteristics in a potential partner using data from 1993 to 1999 provided by a French marriage bureau. We perform an econometric analysis of the various traits either sought or rejected in a potential partner, respectively by men and women. Our results are consistent with investment in marriage. On the one hand, men tend to reject vulgar and unfaithful women, meaning that they are likely to suffer serious fitness costs from infidelity. On the other hand, women dread meeting potential partners who are alcoholic, selfish or violent.
\end{abstract}

Keywords: human mate selection; marriage bureau; gender differences

JEL Codes: C91; D13; D83

\footnotetext{
\# We are indebted to two anonymous reviewers and the Editor, Shoshana Grossbard, for their valuable comments on previous drafts of this paper. The usual disclaimer applies.

* Corresponding author. LEM (UMR 8179 CNRS) and Université Catholique de Lille (Faculté Libre de Sciences Economiques et de Gestion), 60 bd Vauban, BP109, 59016 Lille Cedex, France.

E-mail: nicolas.vaillant@,icl-lille.fr http://ngvaillant.e-monsite.com/

** LEMNA, Université de Nantes, BP52231 Chemin de la Censive du Tertre, 44322 Nantes Cedex; CNAV and INED, Paris, France.

E-mail: francois.wolff@univ-nantes.fr http://www.sc-eco.univ-nantes.fr/ fcwolff/
} 


\section{Introduction}

Extending Becker's seminal analysis of marriage $(1973,1974)$, economists have recently devoted empirical efforts to document the analysis of human mate selection. In terms of the economic theory of consumer behavior described in Lancaster (1966), each potential partner is treated as a bundle of characteristics including age, level of education, physical appearance, intelligence, etc (Hirschmann, 1987, Ford et al., 1989). However, economic contributions focusing on the partner selection process from a consumer behavior analysis point of view remain scarce, Cameron and Collins (1997, 1999, 2000a, 2000b), Batabyal (2001), Le Guirriec and Vaillant (2005) or more recently Choo and Siow (2006) and Fisman et al. (2006, 2008) being exceptions ${ }^{1}$.

Curiously, this stands in contrast with the increasing efforts from psychologists and sociobiologists to further study the analysis of human mate selection. They usually use data from personal advertisements appearing in newspapers (Harrison and Saeed, 1977, Sitton and Rippee, 1986, Rajecki et al., 1991, Thiessen et al., 1993, Buss, 1994, Pawlowski and Koziel, 2002). Such data possess interesting statistical qualities and the personality self-descriptions in these ads seem to be rather fair (Deaux and Hanna, 1984, Baize and Schroeder, 1995). However, the amount of information related to stipulated preferences and personal characteristics is generally restricted by the advertiser him/herself (Pawlowski and Dunbar, 1999). In particular, little is known about his/her preferences in a mate.

The main results of these empirical studies are in line with evolutionary predictions on the dynamics of human mate markets (Pawlowski, 2000). In conformity with the Bateman's Principle (Waynforth and Dunbar, 1995), women are expected to prefer men who are capable of investing in them and their offspring, usually from a financial point of view; this implies that women have a greater preference for slightly older men, usually accompanied by a greater earning potential. Men are more likely to pursue short-term relationships; they are therefore less demanding (Symons, 1979, Buss and Schmitt, 1993), unless they make up their mind to invest in a stable relationship. In this case, they should place greater importance than women in youth and health in a potential partner, in relation to reproductive values and fertility.

Both economic and psychological studies have certainly advanced our understanding of what individuals are looking for in a (new) partner. They corroborate that the wish to marry

\footnotetext{
${ }^{1}$ But there is a growing number of papers inspired by Becker's analysis of marriage. See for instance Boulier and Rosenzweig (1984), Bergstrom and Bagnoli (1993), Grossbard-Shechtman (1995, 2003), Bergstrom (1996), Burdett and Coles (1997), Danziger and Neuman (1999) among others.
} 
has an economic dimension. Single people are searching for potential mates able to provide good companionship, who enjoy similar tastes and interests (Posner, 1992). However, the previous empirical analyses have focused on stipulated "positive" preferences of advertisers, i.e. on characteristics sought in a partner. While individuals living alone have strong preferences on the desired characteristics they search for in partners, there are certainly some traits that they do not want to find during the spousal search.

So far, the question of undesirable characteristics in a mate has been largely unexplored, to the best of our knowledge. At first sight, this is surprising as this information may be valuable from an economic point of view. Because of the uncertainty inherent in searching for a spouse and the uncertainty of the future quality and state of the marriage itself, risk attitudes should impact the description of what candidates to marriage consider as desirable or undesirable traits. For instance, people with a high propensity to reject some potentially "negative" characteristics in a mate should reveal an aversion towards risk. According to Spivey (2009), women are more likely to fall into that case.

Experience in marriage may also play an important role in the expression of negative preferences, in conformity with evolutionary predictions on the dynamics of human mate markets. More precisely, divorced or separated women should be less discriminating and therefore less likely to assume an attitude of rejection, insofar as they have a shorter reproductive life compared to young women, often perceived by men as potential mothers capable of producing healthy children (Buss and Schmitt, 1993). With respect to the role of children upon the demand for partners, women often dread potential partners who are unwilling or unable (due to time and/or money) to invest in them and their (new) offspring (Feingold, 1992). At the same time, child rearing is a time consuming activity and individuals with dependent children could be less demanding, translating into fewer undesirable characteristics being rejected.

So, the expression of negative preferences is expected to convey a specific strategy of marriage investment. Given the lack of empirical evidence so far on undesirable traits in potential partners, we use individual data from the file of a French marriage bureau to explore this issue. Since the data include information both on positive and negative preferences, we study whether the determinants of negative preferences differ from those of positive preferences. We consider different outcomes in our empirical analysis. On the one hand, we focus on the number of characteristics quoted respectively for desired physical and nonphysical characteristics and undesirable characteristics, refusing children being treated as 
another specific case. On the other hand, we study the determinants of the most often quoted traits by men and women, either sought or rejected.

We rely on standard econometric techniques to explain respectively the number of words and specific characteristics sought and rejected by the clients (seemingly unrelated regressions, Probit models). We evidence large differences between male and female clients and highlight the role of economic and physical characteristics of the clients on their preferences. The remainder of our paper is organized as follows. We describe the data that we use in Section 2. We present our results from an econometric analysis of demanded and rejected characteristics in Section 3. Finally, Section 4 concludes.

\section{Data and descriptive statistics}

\subsection{Description of the data}

The data that we use for our empirical analysis are drawn from a marriage bureau located in a provincial French town. They cover the period from March 1993 to December 1999. The data set includes 388 men and 343 women, who may be single, divorced, separated or widowed.

In France, the "Neiertz" act of 1991 regulates the conduct of the matchmaking industry. Meetings have to be between unattached people in order to produce a durable and stable union. Thus, the list of clients of an agency should include only the currently unattached persons who have serious long-term intentions with respect to forming a relationship. ${ }^{2}$ This implies that there is a rigorous control for the maintenance of heterogeneity of intentions amongst advertisers and avoidance of frivolous applicants in the data set used (Le Guirriec and Vaillant, 2005). The amount of bluffing and distortion in any such descriptions should be less than in the personal advertisement data, as the function of the bureau is to check the accuracy of statements and reject liars (Vaillant, 2004).

Following Koziel and Pawlowski (2003), we choose to exclude both widows and widowers from the sample (respectively 42 men and 54 women). The main argument is that they are "victims" of their marital status, related to the death of their previous partner. This means that they are more likely to be registered in the bureau for reasons other than those linked to a lack of productivity in marriage. Unlike individuals who had never been married

\footnotetext{
${ }^{2}$ Some surveys indicate that almost 100,000 individuals use the services of a marriage bureau in France each year $(10 \%$ of single people $)$. See for instance http://demotango.expertinfos.com/_infos/_tango/creation.asp?article=etude_rencontre_chap1_3\&repertoire=\&ancre=ancre1\&titrerubriq $\mathrm{ue}=$ marcherencontre
} 
or separated/divorced, widows and widowers are expected to pursue "involuntary" mating strategies and they are on average much older than the other participants. ${ }^{3}$

Also, we make a distinction between persons without marital past and divorced or separated individuals. The former case corresponds to the "primary mate market". This subsample includes 143 female and 202 male single persons. The second subsample, which defines the "secondary mate market", includes 146 and 143 divorced or separated women and men respectively. The limitations of the sample are twofold. First, the sample remains somewhat small. Secondly, it concerns French people from a provincial town who pay to find a mate.

When joining a matchmaking agency, each client has to fill in an information sheet, in which he/she describes his/her own characteristics and the features he/she seeks in a potential partner. Unfortunately, we are not able to look at how cognitive processes and conversational principles affect both the interaction between clients and the agency and the quality of the eventual answers (Ongena and Dijkstra, 2007). There is first information on gender and age. Each respondent also indicates whether he/she has any dependent child or not. The level of education is measured through a dummy variable which is equal to one when the client holds a University degree (and zero otherwise). The second economic indicator consists in the current level of earned income per month (expressed in Euros). Note that there is no information on assets or holdings in the survey.

Because the aim of a matchmaking agency is to lead to durable and serious meetings, the quality of the marriage proposals depends on the way in which the service "selects" the market. This selection is achieved through price discrimination on the basis of official and objective criteria (age, gender, duration of subscription) and on other factors like being divorced or possessing wealth for women (Vaillant, 2004). For instance, the subscription price amounts to 600 Euros for three months for a man, 450 Euros for a woman older than 30, and 300 Euros for a younger woman. The marriage bureau seeks to promote subscriptions among individuals having "good" characteristics by offering them a lower price. By contrast, clients who have a small number of desirable characteristics will pay higher prices.

Since we know for each client the price paid to the matchmaking agency, we construct an estimation of the real investment of the clients in mating strategies. Specifically, we divide the amount of money they spent in matchmaking services by their own level of income.

\footnotetext{
${ }^{3}$ In the sample, widows and widowers are 59.3 and 58.2 years old respectively. Also, it should be noted that women are outside their reproductive period of life. For a detailed description of the 'widow' subsample, see Vaillant (2004).
} 
Finally, the last set of variables deals with physical characteristics. The data do not include any direct measure of physical attractiveness, but there is some information on both height (in meters) and weight (in kilograms). We combine these two features to calculate the body mass index (BMI), which is the commonly used ratio between weight and the square of height (Sarlio-Lähteenkorva and Lahelma, 2001).

We follow the approach developed in the psychological literature on personal advertisements (Waynforth and Dunbar, 1995) to construct our dependent variable related to individual preferences on human mate selection. We measure the client's requirement concerning the characteristics he/she seeks or rejects in a potential partner by counting the number of corresponding words used by the client. We identify the three following categories: number of physical characteristics sought, number of non-physical characteristics sought, and number of undesirable non-physical characteristics. Finally, we consider an additional case, which is whether the client refuses a partner with one or several dependent children. We have then two variables measuring undesirable characteristics in potential partners.

\subsection{Descriptive statistics}

We present descriptive statistics of the characteristics of the clients in Table 1, both for the primary and secondary mate markets. The following comments are in order. First, female clients are on average slightly older than male clients, 41.8 instead of 40.7 for divorced or separated persons. Also, the mean age of clients on the primary mate market is significantly higher than the mean age at first marriage observed in France, 28.5 years among men and 26.6 years among women (Prioux, 1999). This age mismatching casts doubt on the success of finding a partner with the help from a matchmaker, but the same is true in lonely hearts columns (Lemennicier, 1988, Vaillant, 2006). While the marital intermediary cannot influence the objective characteristics of the clients (like age or education), it may still help improve the odds of "success" of both the male and female clients by acting on the demand side, through their requirements (Ahuvia and Adelman, 1992). ${ }^{4}$

\section{Insert Table 1 here}

Another result from the data is that women invest less than men in matchmaking services, the largest gap being observed on the primary market. For that population, male and female monthly incomes are not so different, respectively 1438 and 1310 Euros. However, the price paid to the agency by men is more than 2.5 times higher than the price paid by women

\footnotetext{
${ }^{4}$ With the same data, Vaillant and Harrant (2008) find that despite the age mistmatching, $26.8 \%$ and $29.4 \%$ of men and women of the sample have found a partner through the agency between 1993 and 1999.
} 
(991 Euros instead of 385). The difference in price paid to the agency partially explains why men invest relatively more than women in such matchmaking services. The investment rate amounts to $82.5 \%$ among men and $37.9 \%$ among women on the primary market. These proportions are equal to $68 \%$ and $51.5 \%$ on the secondary market. The discrepancy could also be explained by gender differences in marital search strategies, but there is no reliable information in the data to further explore this hypothesis.

We also describe in Table 1 the pattern of the characteristics demanded or rejected by the clients. Recalling that our indicators rely on the number of words, we find that women are on average more verbal than men when they describe the features they seek or reject in partners. However, this pattern does not hold for all outcomes under consideration since the difference in the mean number of words between women and men is really small for physical attributes, respectively 1.5 instead of 1.4. The gender gap is much higher for non-physical attributes (3.3 instead of 1.5) than for undesirable characteristics (2.1 instead of 1.7). Interestingly, there is not much difference in the number of words between clients of the primary and secondary mate markets. The histograms of both female and male talkativeness for each outcome are further shown in Figure 1.

\section{Insert Figure 1 here}

The main difference between the two markets lies in the percentage of clients claiming that they refuse children. The proportion is about $70 \%$ on the primary mate market, but it is much lower for clients of the secondary market, respectively $18.3 \%$ among men and $27.9 \%$ among women. A last note is that the more detailed description provided by women of what they are looking for does not mean that they are more demanding. Indeed, an individual may seek or reject only one very specific characteristic in a partner.

\section{An econometric analysis of demanded and rejected characteristics}

\subsection{Explaining the number of words associated to preferences}

We begin with an exploration of the determinants of the number of words given for sought or rejected characteristics. For the presentation, we denote by $P C, N C, U C$ and $R C$ the number of words quoted by each client respectively for physical characteristics, non-physical characteristics, undesirable characteristics and refusing children. Note that $P C, N C$ and $U C$ are continuous dependent variables, while $R C$ is a binary variable. We estimate the following model: 


$$
\left\{\begin{array}{l}
P C=X^{\prime} \beta_{P C}+\varepsilon_{P C} \\
N C=X^{\prime} \beta_{N C}+\varepsilon_{N C} \\
U C=X^{\prime} \beta_{U C}+\varepsilon_{U C} \\
R C=X^{\prime} \beta_{R C}+\varepsilon_{R C}
\end{array}\right.
$$

where $\varepsilon_{P C}, \varepsilon_{N C}, \varepsilon_{U C}$ and $\varepsilon_{R C}$ are four error terms normally distributed. As the unobserved factors that influence the different outcomes are likely to be correlated, we assume the following distribution for the random perturbations:

$$
\left(\begin{array}{l}
\varepsilon_{P C} \\
\varepsilon_{N C} \\
\varepsilon_{U C} \\
\varepsilon_{R C}
\end{array}\right) \sim \mathrm{N}\left(\begin{array}{llccc}
0 & \sigma_{\mathrm{PC}}^{2} & \rho_{P C-N C} & \rho_{P C-U C} & \rho_{P C-R C} \\
0 & & \sigma_{\mathrm{NC}}^{2} & \rho_{N C-U C} & \rho_{N C-R C} \\
0 & & & \sigma_{\mathrm{UC}}^{2} & \rho_{U C-R C} \\
0 & & & 1
\end{array}\right)
$$

The system defined by (1) comprises three continuous equations and one Probit equation. We choose to estimate (1) through a seemingly unrelated regressions framework, i.e. we treat the equations as independent from each other except for their underlying error terms (which are jointly normally distributed). Since we have different kinds of dependent variables, we turn to a mixed process estimator and rely on a maximum likelihood method (Roodman, 2009). The various results are shown in Table 2.

\section{Insert Table 2 here}

The evidence indicates large differences between men and women. In line with previous research based on lonely-hearts columns, we observe in the whole sample (Panel A of Table 2) that women attach much more importance than men to non-physical characteristics. On average, they quote 1.8 additional words with respect to men. They also use more words ( +0.4 words on average) to describe the characteristics they do not want in potential partners. This may be interpreted as a greater risk aversion against poor partners. In contrast, there is no significant difference between men and women when considering physical characteristics and the refusal of children.

Surprisingly, when considering the primary mate market (Panel B), we find that women are less likely than men to refuse partners with dependent children, whereas the reverse pattern holds for women with experience in marriage at the 10 percent level (Panel C). A possible explanation is that the former experience more difficulties to find a partner on their own (Le Guirriec and Vaillant, 2005). Also, women may become less demanding as time goes by given their short fertility period and women on the secondary market feel less urgency about having children, so they are more picky in this respect. A further explanation is that women perform more work in household production when they have kids. Therefore, on the 
secondary mate market, a man with children is more often a burden for women than a woman with children is a burden for men. This relates to the concept of work-in-marriage and spousal labor discussed in Grossbard-Shechtman (1995).

Concerning age, we find that older clients are more likely to accept a new mate who is a parent. In the primary market subsample, older clients are also more demanding about physical characteristics, whereas they attach less importance to undesirable characteristics in the secondary mate market subsample (at the 10 percent level). In the same vein, clients who have children have a lower probability of refusing children (Panel A, Table 2). Child rearing is a time consuming activity, and there are substantial economies of scale with a large family. Also, parents must be less demanding as having parental ties tends to reduce their own level of attraction in the eyes of potential partners. Finally, we note that there is no significant relationship between having children and the other desired or undesired characteristics.

Results described in Table 2 show that physical appearance plays an important role on marital demand. First, when clients of the agency on the secondary mate market are overweight (i.e. their BMI is above 25), they attach less importance to physical features in potential partners; in this case, the number of words is reduced by 0.2 . Heavier individuals tend to be less attractive in Western societies. They may suffer from exclusion and they will experience higher costs of finding a satisfying partner due to lower physical attractiveness. Interestingly, we note that overweight is only significant on the primary mate market. This situation makes the clients less demanding in terms of physical appearance in a new mate. ${ }^{5}$

In contrast, under-weight individuals (i.e. with a BMI lower than 18.5) appear to be more demanding about physical appearance, especially when they are on the primary mate market. In that case, the number of words related to physical characteristics increases by 0.4 . Note that this positive relationship does not hold among more experienced clients. On the secondary mate market, underweight clients tend to be more verbal to describe the traits they do not wish for in a mate (at the 10 percent level). This also reflects a better marriage market position available to thin people.

Clients who have graduated from University use more words to describe the physical features they are looking for, both on the primary and the secondary market. On the former market, more educated clients are also more likely to refuse children. Another result is that the investment variable does not play a significant role in the secondary market subsample.

\footnotetext{
${ }^{5}$ According to the data, clients in the overweight category are slightly more demanding about the characteristics they do not wish in a new mate, but the corresponding effect is not significant at conventional level.
} 
This suggests that individuals in this category do not pay to improve the quality of a potential mate, but simply to increase their odds of meeting a potential partner.

Curiously, we get a negative relationship between the number of words used to describe both non-physical and physical traits and the level of investment. ${ }^{6}$ On a priori grounds, one would expect a positive effect as clients investing more in the marital search should be more demanding. Several explanations may come to mind. Clients who choose to invest more may have no accurate idea about the characteristics they are looking for. Also, they may look for some very particular traits in their partners, which would translate to a very small number of exact words. ${ }^{7}$ Another explanation is that they have some unobserved negative traits, which lead them to invest more in marital agency and to be less picky.

A shortcoming of Table 2 is undoubtedly that we have pooled both the male and female subsamples of clients. This is certainly too restrictive since there may be some gender differences in the impact of various characteristics; for instance, over-weight is expected to reduce requirements of women more than men (Mukhopadhyay, 2008). We have then reestimated the seemingly unrelated regressions with a set of interaction terms with gender, respectively for age, having children, higher education, under-weight and over-weight. Our results, available upon request, show little difference between men and women for the various outcomes. The only significant results are as follows. On the one hand, we find that higher educated women are less likely than men to refuse children. It could be argued that these women favor more their professional life and would be less tempted to deliver birth. On the other hand, under-weight women indicate fewer non-physical characteristics than underweight-men do, while the reverse pattern holds for undesirable characteristics. These women may be simply more demanding, but these results related to weight have to be interpreted with cautious given the limited size of our sample.

\subsection{More on the sought and undesirable characteristics in partners}

To overcome the difficulty set by the number of words quoted when measuring preferences for specific traits, we now turn to a more disaggregated analysis where we focus on explicit characteristics sought or rejected in potential partners by the clients of the agency.

\footnotetext{
${ }^{6}$ We also find a negative relationship between the level of investment and the refusal of children. It may be that clients investing more money in the spousal search strongly wish to live as a couple, therefore being less demanding on the characteristics of the partner.

${ }^{7}$ The latter indicator may thus be somewhat problematic to differentiate between clients who have no clear preferences (therefore tempted to give a large set of sought traits) and those who are in search of a very limited number of traits corresponding to well-defined preferences.
} 
We rely on a set of seven frequently quoted words for each outcome: pleasant, femininity, thin, charming, tall, dark-haired and elegant for physical characteristics; gentle, thoughtful, kind, frank, strong personality, dynamic and open for non-physical characteristics; vulgar, smoker, unfaithful, liar, selfishness, alcohol and violence for undesirable characteristics.

Both for men and women, we describe the proportion of clients reporting each of these words in Table 3. According to the data, female physical requirements are more specific and more objective than for men: $41 \%$ and $10 \%$ of women look for a tall and a dark-haired spouse respectively, while the most recurrent objective male demand is that $12.3 \%$ for a thin spouse. The subjective physical traits correspond to characteristics that cannot really be measured, like "charming", which is quoted by $9.9 \%$ of men and $16.9 \%$ of women. Women seek an elegant man (5.2\%), while men seek a feminine partner (14.8\%).

\section{Insert Table 3 here}

The recurrence of "pleasant" (47.9\% among men, 45\% among women) may be explained by the fact that the agency has to propose to the client a potential partner having the characteristics he/she sought. In other words, the agency should respect the exact requirement of the client, i.e. the words used in the information sheet. In practice, the agency tries to mitigate this constraint in two ways. On the one hand, it offers a counseling service to explain that there is a "rate of substitution" between the characteristics of a partner (Posner, 1992): one or several "good" characteristics may compensate for unsought characteristics. ${ }^{8}$ On the other hand, the intermediary sometimes writes the information sheet in order to use words as evasive as possible in the declaration of the requirement.

The analysis of the non-physical sought characteristics indicates that men and women have similar requirements of potential partners for the following traits: kind ( $12 \%$ both for male and female clients), frank (11.1\% for men, $14.1 \%$ for women), and strong personality (respectively $10.5 \%$ and $8.8 \%$ ). Female demand is more diversified: they seek thoughtful (22.5\%), vigorous $(21.1 \%)$, well-educated $(11.4 \%)$ and/or open partners, and mates with a good sense of humor $(11.8 \%)$. The most frequently trait sought by men among women is gentle $(33.7 \%)$, which is less frequently quoted by women $(12.4 \%)$. The female demand for non-physical characteristics is more diversified. The partners they seek have to be thoughtful $(32.5 \%)$, dynamic $(15.3 \%)$ and open $(10.8 \%)$.

\footnotetext{
${ }^{8}$ Examples would be the case of a woman who is indifferent to the physical appearance of her new husband as long as the latter has a large income or a man who agrees to meet a woman with dependent children if she is a thin and intelligent woman.
} 
Finally, the undesirable traits reported by the clients are not in conflict with the nonphysical characteristics sought and they are fully coherent with marriage investment strategies. First, both men and especially women reject partners who smoke $(13.6 \%$ and $22.5 \%$ respectively). The proportion of men who reject a vulgar potential partner is higher than that of women, respectively $19.9 \%$ versus $8.4 \%$. This may be explained by the fact that men are likely to suffer serious fitness costs from cuckoldry and this should result in men making indirect and direct demands for cues of sexual fidelity (Buunk et al., 2001). Other characteristics dreaded by the female clients are linked to the incapacity or the unwillingness of males to invest in them and their offspring (Feingold, 1992). This is related to the following words: alcoholic (16.9\%), selfish (12.4\%), violent (10.8\%) and liar (9.2\%).

To further understand preferences in human mate selection, we turn to Probit models to estimate the probability of a specific trait being quoted. We perform this estimation both for desirable and undesirable characteristics and only consider the four traits that are most often quoted respectively by men and by women. ${ }^{9}$ We calculate the marginal effect of each individual characteristic on the probability of reporting a specific word, and report the corresponding results in Table 4. A few estimates are statistically significant.

\section{Insert Table 4 here}

The level of education influences answers provided for physical characteristics sought. In particular, well-educated women are more often looking for tall men. A first explanation is that some women take height into account as an anticipated indicator of future resources of the household. This is in accordance with the findings of Herpin (2005), who shows that tall men have better careers than short men with identical educational attainment levels. More generally, physical stature plays an important role in human mate choice because it may signal dominance, high status, access to resources, and underlying heritable qualities (Salska et al., 2008). ${ }^{10}$

Another interpretation is related to some positive sorting by height. If more educated women are taller themselves, then they would have preferences for taller partners. We have thus compared the height of low educated and high educated women using our data. The difference in height between the two groups is equal to 2 centimeters and is significant at the 1 percent level (with a t-value of 2.69). At the same time, it should be noted that we already

\footnotetext{
${ }^{9}$ Although we have four outcomes for each respondent, we choose to estimate independent Probit equations. For the sake of robustness, we have also estimated quadrivariate Probit models to control for the possible correlation between the residual of each single Probit equation. This does not affect our conclusions and the multivariate results are available upon request.

${ }^{10} \mathrm{We}$ also observe from Table 4 that high educated men are more often looking for feminine and thin partners.
} 
control for height in our regression since the BMI is included in the list of covariates.

When they are parents, men are specifically searching for gentle and kind mates. They also reject unfaithful women, which corroborates the idea that they are looking for a mate able to help them to raise their children (Daly et Wilson, 1983). Male clients who pay a relatively high price to the agency attach little importance to femininity and try to avoid unfaithful and lying partners. These findings are in favor of a male strategy of marriage investment. At the same time, these men may simply be less attractive, and hence less demanding of traits associated with attractive women. Conversely, there is no significant relationship between the investment variable and the various specific outcomes among women.

Physical appearance affects both women and men of the sample. When they are underweight, female clients are more often looking for dark-haired males and consider selfishness as a negative characteristic. Heavy-built women are less likely to report the words tall and charming. This is not surprising as they presumably experience larger costs of finding a physically satisfying partner due to their lower physical attractiveness relative to thin females. Over-weight males expect gentle and kind mates. They also attach less importance to physical appearance of partners, insofar as "thin" is not a word they use to describe the physical appearance of a potential mate (at the 10 percent level).

Finally, we observe differences in preferences about non-physical characteristics between clients who are on the primary mate market and those who have experience in union. Male clients on the secondary mate market are more likely to search for frank women, while they are less likely to use the words gentle and kind. Female clients on the primary mate market are more often looking for a dynamic mate. There is no significant difference between the primary and the secondary market when considering physical and undesirable characteristics. Experience is certainly not necessary for women to know that they want to avoid violent or selfish male partners.

\section{Conclusion}

In this paper, we have used original data from a French marriage bureau to extend previous empirical analyses of characteristics sought in partners, usually based on personal advertisements data. Specifically, we have analyzed the determinants of both sought and rejected traits, i.e. characteristics that single persons either desire or do not desire in potential partners.

We find evidence of large differences both in sought and rejected characteristics by gender. On average, men tend to reject vulgar and unfaithful women, suggesting that they are 
likely to suffer serious fitness costs from cuckoldry. Women, on their hand, dread to meet potential partners who are alcoholic, selfish, violent and/or liars, i.e. partners who are less likely to invest in them and their offspring. We also find that overweight clients attach less importance to physical features in potential partners and that highly educated women are more often looking for tall men, assumed to be economically more advantageous.

As it stands, our descriptive contribution has to be seen as a first attempt to document both positive and negative preferences in human mate selection. It would be interesting to further study how these preferences for sought and rejected traits influence the probability of finding a partner. Do clients really find a partner using the bureau file when they are too demanding? Does it increase time needed to find a partner? Do clients become less demanding regarding undesirable characteristics, as their search remains unfruitful? Do they attach more weight to the characteristics they seek in a potential partner, or to the traits they absolutely do not want to find? Also, it would be worthwhile to assess the consequences of these requirements on the duration of the union for those who find a partner. All these issues of interest, which require longitudinal data, are left for future research.

\section{References}

Ahuvia, A., \& Adelman, M. (1992). Formal intermediaries in the marriage market: A typology and review. Journal of Marriage and the Family, 54, 452-463.

Batabyal, A.A. (2001). On the likelihood of finding the right partner in an arranged marriage. Journal of Socio-Economics, 33, 273-280.

Baize, H., \& Schroeder, J.E. (1995). Personality and mate selection in personal ads: evolutionary preferences in a public mate selection process. Journal of Social Behavior Personality, 10, 517-536.

Becker, G.S. (1973). A theory of marriage: part one. Journal of Political Economy, 81(4), 813-846.

Becker G.S. (1974). A theory of marriage: part two", Journal of Political Economy, 82(2), S11-S26.

Bergstrom, T.C. (1996). Economics in a family way. Journal of Economic Literature, 34(4), 1903-1934.

Bergstrom, T.C., \& Bagnoli, M. (1993). Courtship as a Waiting Game”, Journal of Political Economy, 101(1), 185-203.

Boulier, B., \& Rosenzweig, M. (1984). Schooling, search and spouse selection: Testing the economic theories of marriage and household behavior. Journal of Political Economy, 92(4), 712-732. 
Burdett, K., \& Coles, M.G. (1997). Marriage and class. Quarterly Journal of Economics, 112(1), 141-168.

Buss, D.M. (1994). The evolution of desire: Strategies of human mating. New York: Basic Books.

Buss, D.M., \& Schmitt, D.P. (1993). Sexual strategies theory: An evolutionary perspective on human mating. Psychological Review, 100, 204-232.

Buunk, B.P., Dijkstra, P., Kenrick, D.T., \& Warntjes, A. (2001). Age preferences for mates as related to gender, own age, and involvement level. Evolution and Human Behavior, 22, 241-250.

Cameron, S., \& Collins, A. (1997). Estimates of a hedonic ageing equation for partner search. Kyklos, 40, 409-418.

Cameron, S., \& Collins, A. (1999). Looks unimportant? A demand function for male attractiveness by female personal advertisers. Applied Economics Letters, 6, 381-384.

Cameron, S., \& Collins, A. (2000a). Random utility maximizer seeks similar: an economic analysis of commitment level in personal relationships. Journal of Economic Psychology, 21, 73-90.

Cameron, S., \& Collins, A. (2000b). Playing the Love Market: Dating, Romance and the Real World. London: Free Association Books.

Choo, E., \& Siow, A. (2006), Who Marries Whom and Why. Journal of Political Economy, $114,175-201$.

Daly, M., \& Wilson, M. (1983). Sex: Evolution and behavior. Boston, MA: Willard Grant.

Danziger, L., \& Neuman, S. (1999). On the age at marriage: theory and evidence from Jews and Moslems in Israel. Journal of Economic Behavior and Organization, 40, 179-193.

Deaux, K., \& Hanna, R. (1984). Courtship in the personnals column: the influence of gender and sexual orientation. Sex roles, 11(5-6), 363-375.

Feingold, A. (1992). Gender differences in mate selection preferences: A test of the parental investment model. Psychological Bulletin, 112, 125-139.

Fisman, R., Iyengar, S., Kamenica, E., \& Simonson, I. (2006). Gender Differences in Mate Selection: Evidence from a Speed Dating Experiment. Quarterly Journal of Economics, 121, 673-697.

Fisman, R., Iyengar, S., Kamenica, E., \& Simonson, I. (2008). Racial Preferences in Dating. Review of Economic Studies, 75, 117-32.

Ford, K., Schmitt, N., Shechtman, S., Hults, B.M., \& Doherty, M.L. (1989). Process Tracing Methods: Contributions, Problems, and Neglected Research Questions. Organizational Behavior and Human Decision Processes, 43(1), 75-117.

Grossbard-Shechtman, S. (1995). Marriage market models. In Tomassi, M. and K., Ierulli, (eds.), The new economics of human behavior. Cambridge: Cambridge University Press.

Grossbard-Shechtman, S. (2003). A consumer theory with competitive markets for work in marriage. Journal of Socio-Economics, 31, 609-645.

Harrison, A.A., \& Saeed, L. (1977). Let's make a deal: An analysis of revelations and stipulations in lonely hearts advertisements. Journal of Personality and Social Psychology, $35,257-264$. 
Herpin, N. (2005). Love, careers, and heights in France, 2001. Economics and Human Biology, 3(3), 420-449.

Hirschman, E. (1987). People as products: analysis of a complex marketing exchange. Journal of Marketing, 51, 98-108.

Koziel, S., \& Pawlowski, B. (2003). Comparison between primary and secondary mate markets: an analysis of data from lonely hearts columns. Personality and Individual Differences, 35, 1849-1857.

Lancaster, K. (1966). A New Approach to Consumer Theory. Journal of Political Economy, $74(2), 132-157$.

Le Guirriec, G., \& Vaillant, N. (2005). From Libertinism to Marital Commitment: The Economics of Marital Research with Heterogeneous Agents. Journal of BioEconomics, 7(1), 84-94.

Lemennicier, B. (1988). Le marché du mariage et de la famille. Presses universitaires de France, coll. Libre échange.

Mukhopadhyay S., (2008). Do women value marriage more? The effect of obesity on cohabitation and marriage in the USA. Review of Economics of the Household, 6(2), 111126.

Ongena, Y.P. \& Dijkstra, W. (2007). A Model of Cognitive Processes and Conversational Principles in Survey Interview Interaction. Applied Cognitive Psychology, 21, 145-163.

Pawlowski, B. (2000). The biological meaning of preferences on the human mate market. Anthropological Review, 63, 39-72.

Pawlowski, B., \& Dunbar, R.I.M. (1999). Withholding age as putative deception in mate search tactics. Evolution and Human Behavior, 20, 53-69.

Pawlowski, B., \& Koziel, S. (2002). The impact of traits in personal advertisements on response rate. Evolution and Human Behavior, 23, 139-149.

Posner, R. (1992). Sex and Reason. Cambridge Ma: Harvard University Press.

Prioux, F. (1999). La conjoncture démographique en France. Population, 54(3), 446-479.

Rajecki, D.W., Bledsoe, S.B., \& Rasmussen, J.L. (1991). Successful personal ads: Gender differences and similarities in offers, stipulations and outcomes. Basic and Applied Social Psychology, 12, 457-469.

Roodman, D. (2009). Estimating Fully Observed Recursive Mixed-Process Models with cmp. Mimeo, Working Papers 168, Center for Global Development.

Salska, I., Frederick, D.A., Pawlowski, B., Reilly, A.H., Laird, K.T., \& Rudd, N.A. (2008). Conditional mate preferences: Factors influencing preferences for height. Personality and Individual Differences, 44, 203-215.

Sarlio-Lähteenkorva, S., \& Lahelma, E. (2001). Food insecurity is associated with past and present economic disadvantage and body mass index. Journal of Nutrition, 131, 28802884.

Sitton, S., \& Rippee, E.T. (1986). Women still want marriage: Sex differences in lonely hearts advertisements. Psychological Reports, 58, 119-123.

Spivey, C. (2009). Desperation or desire? The role of risk aversion in marriage. Economic Inquiry, forthcoming. 
Symons, D. (1979). The evolution of human sexuality. New York: Oxford University Press.

Thiessen, D., Young, R.K., \& Burroughs, R. (1993). Lonely hearts advertisements reflect sexually dimorphic mating strategies. Ethology and Sociobiology, 14, 209-229.

Vaillant, N.G. (2004). Discrimination in matchmaking: evidence from the price policy of a French marriage bureau. Applied Economics, 36, 723-729.

Vaillant, N.G. (2006). Sex differences in stipulated preferences and mate search efforts by clients of a French marriage bureau. Psychological Reports, 98, 285-290.

Vaillant, N.G., \& Harrant, V. (2008). On the likelihood of finding the right partner in an arranged marriage: Evidence From a French Marriage Bureau. Journal of SocioEconomics, 32, 657-671.

Waynforth, D., \& Dunbar, R.I.M. (1995). Conditional mate choice strategies in humans: Evidence from "lonely hearts" advertisements. Behaviour, 132, 755-779. 
Table 1. Descriptive statistics of the sample, by marital status and gender

\begin{tabular}{|c|c|c|c|c|c|c|c|c|}
\hline \multirow{3}{*}{ Variables } & \multicolumn{4}{|c|}{ Primary Mate Market } & \multicolumn{4}{|c|}{ Secondary Mate Market } \\
\hline & \multicolumn{2}{|c|}{ Men } & \multicolumn{2}{|c|}{ Women } & \multicolumn{2}{|c|}{ Men } & \multicolumn{2}{|c|}{ Women } \\
\hline & mean & s.d. & mean & s.d. & mean & s.d. & mean & s.d. \\
\hline \multicolumn{9}{|l|}{ Independent variables } \\
\hline Age & 30.673 & 5.874 & 31.140 & 8.817 & 40.722 & 8.647 & 41.788 & 9.481 \\
\hline Children & - & - & - & - & 1.250 & 0.950 & 1.158 & 1.048 \\
\hline Higher education & 0.431 & 0.496 & 0.629 & 0.485 & 0.243 & 0.430 & 0.281 & 0.451 \\
\hline Monthly income (in Euros) & 1438 & 792 & 1310 & 696 & 1721 & 1055 & 1491 & 828 \\
\hline Price (in Euros) & 991 & 434 & 385 & 335 & 972 & 395 & 617 & 407 \\
\hline Investment (price/income) & 0.825 & 0.469 & 0.379 & 0.322 & 0.680 & 0.403 & 0.515 & 0.423 \\
\hline Height & 176.358 & 7.418 & 165.378 & 6.711 & 175.451 & 6.849 & 163.719 & 5.927 \\
\hline Weight & 72.935 & 10.800 & 58.170 & 9.267 & 74.944 & 9.251 & 59.676 & 8.533 \\
\hline BMI*100 & 0.234 & 0.030 & 0.212 & 0.029 & 0.243 & 0.027 & 0.222 & 0.030 \\
\hline \multicolumn{9}{|l|}{ Dependent variables } \\
\hline Physical characteristics & 1.398 & 0.782 & 1.594 & 0.833 & 1.357 & 0.745 & 1.466 & 0.789 \\
\hline Non-physical characteristics & 1.388 & 0.824 & 3.196 & 1.274 & 1.462 & 0.767 & 3.322 & 1.138 \\
\hline Undesirable characteristics & 1.663 & 0.884 & 2.035 & 0.974 & 1.694 & 0.813 & 2.116 & 0.898 \\
\hline Refusing children & 0.733 & 0.444 & 0.714 & 0.453 & 0.183 & 0.388 & 0.279 & 0.450 \\
\hline Number of observations & \multicolumn{2}{|c|}{202} & \multicolumn{2}{|c|}{143} & \multicolumn{2}{|c|}{144} & \multicolumn{2}{|c|}{146} \\
\hline
\end{tabular}


Table 2. Multivariate estimates of desired and undesired characteristics in partner A. All $(N=645)$

\begin{tabular}{|c|c|c|c|c|c|c|c|c|}
\hline \multirow[t]{2}{*}{ Variables } & \multicolumn{2}{|c|}{$\begin{array}{c}\text { Physical } \\
\text { characteristics }\end{array}$} & \multicolumn{2}{|c|}{$\begin{array}{l}\text { Non-physical } \\
\text { characteristics }\end{array}$} & \multicolumn{2}{|c|}{$\begin{array}{c}\text { Undesirable } \\
\text { characteristics }\end{array}$} & \multicolumn{2}{|c|}{ Refusing children } \\
\hline & coef & t-value & coef & t-value & coef & t-value & coef & t-value \\
\hline Constant & 1.295 & 8.11 & $1.646^{* * *}$ & 8.16 & $1.830^{* * *}$ & 9.84 & $1.764^{* * *}$ & 5.74 \\
\hline Woman & 0.025 & 0.36 & $1.803^{* * *}$ & 20.07 & $0.418^{* * *}$ & 5.06 & -0.042 & -0.32 \\
\hline Age & 0.006 & 1.52 & -0.002 & -0.38 & -0.007 & -1.42 & $-0.033^{* * *}$ & -4.20 \\
\hline Children & -0.009 & -0.18 & -0.030 & -0.50 & 0.005 & 0.08 & $-0.322^{* * *}$ & -3.11 \\
\hline Higher education & $0.165^{* *}$ & 2.33 & 0.031 & 0.34 & 0.041 & 0.49 & 0.183 & 1.43 \\
\hline Investment & $-0.142^{*}$ & -1.83 & $-0.288^{* * *}$ & -2.94 & -0.024 & -0.26 & $-0.337^{* *}$ & -2.32 \\
\hline BMI: underweight & $0.295^{*}$ & 1.82 & -0.220 & -1.09 & 0.249 & 1.34 & 0.189 & 0.65 \\
\hline BMI: overweight & $-0.184^{* *}$ & -2.27 & 0.090 & 0.87 & 0.111 & 1.17 & -0.062 & -0.41 \\
\hline Secondary mate market & -0.085 & -0.85 & 0.086 & 0.68 & 0.104 & 0.89 & $-0.639^{* * *}$ & -3.47 \\
\hline \multirow[t]{3}{*}{ Coefficients of correlations } & 1 & - & $0.103^{* *}$ & 2.47 & $0.161^{* * *}$ & 3.91 & 0.078 & 1.37 \\
\hline & & & 1 & - & $0.086^{* *}$ & 2.06 & 0.067 & 1.16 \\
\hline & & & & & 1 & - & $0.141^{* *}$ & 2.44 \\
\hline Log likelihood & \multicolumn{8}{|c|}{-2511.3} \\
\hline
\end{tabular}

B. Primary mate market $(N=345)$

\begin{tabular}{|c|c|c|c|c|c|c|c|c|}
\hline \multirow[t]{2}{*}{ Variables } & \multicolumn{2}{|c|}{$\begin{array}{c}\text { Physical } \\
\text { characteristics }\end{array}$} & \multicolumn{2}{|c|}{$\begin{array}{l}\text { Non-physical } \\
\text { characteristics }\end{array}$} & \multicolumn{2}{|c|}{$\begin{array}{c}\text { Undesirable } \\
\text { characteristics }\end{array}$} & \multicolumn{2}{|c|}{ Refusing children } \\
\hline & coef & t-value & coef & t-value & coef & t-value & coef & t-value \\
\hline Constant & $1.145^{* * *}$ & 4.79 & $1.779^{* * *}$ & 5.87 & $1.654^{* * *}$ & 5.83 & $2.586^{* * *}$ & 5.37 \\
\hline Woman & 0.011 & 0.10 & $1.782^{* * *}$ & 13.30 & $0.396^{* * *}$ & 3.16 & $-0.471^{* *}$ & -2.39 \\
\hline Age & $0.012^{*}$ & 1.86 & -0.002 & -0.26 & -0.001 & -0.14 & $-0.053^{* * *}$ & -4.17 \\
\hline Higher education & $0.162^{*}$ & 1.78 & 0.017 & 0.14 & 0.097 & 0.89 & $0.339^{* *}$ & 2.00 \\
\hline Investment & $-0.190^{*}$ & -1.81 & $-0.445^{* * *}$ & -3.33 & -0.053 & -0.42 & $-0.514^{* * *}$ & -2.69 \\
\hline BMI: underweight & $0.420^{* *}$ & 2.05 & -0.247 & -0.99 & 0.093 & 0.40 & 0.564 & 1.41 \\
\hline BMI: overweight & -0.152 & -1.29 & 0.035 & 0.23 & 0.133 & 0.95 & -0.030 & -0.14 \\
\hline \multirow[t]{3}{*}{$\overline{\text { Coefficients of correlations }}$} & 1 & - & 0.080 & 1.40 & $0.149^{* * *}$ & 2.62 & 0.071 & 0.91 \\
\hline & & & 1 & - & 0.076 & 1.33 & -0.006 & -0.07 \\
\hline & & & & & 1 & - & $0.245^{* * *}$ & 3.24 \\
\hline Log likelihood & \multicolumn{8}{|c|}{-1352.2} \\
\hline
\end{tabular}

C. Secondary mate market $(N=290)$

\begin{tabular}{|c|c|c|c|c|c|c|c|c|}
\hline \multirow{3}{*}{$\begin{array}{l}\text { Variables } \\
\text { Constant }\end{array}$} & \multicolumn{2}{|c|}{$\begin{array}{c}\text { Physical } \\
\text { characteristics }\end{array}$} & \multicolumn{2}{|c|}{$\begin{array}{l}\text { Non-physical } \\
\text { characteristics }\end{array}$} & \multicolumn{2}{|c|}{$\begin{array}{c}\text { Undesirable } \\
\text { characteristics }\end{array}$} & \multicolumn{2}{|c|}{ Refusing children } \\
\hline & coef & t-value & coef & t-value & coef & t-value & coef & $\mathrm{t}$-value \\
\hline & $1.410^{* * *}$ & 5.35 & $1.645^{* * *}$ & 4.95 & $2.070^{* * *}$ & 6.88 & 0.382 & 0.74 \\
\hline Woman & 0.027 & 0.28 & $1.790^{* * *}$ & 14.68 & $0.426^{* * *}$ & 3.86 & $0.309^{*}$ & 1.65 \\
\hline Age & 0.001 & 0.14 & -0.003 & -0.45 & $-0.010^{*}$ & -1.64 & $-0.019^{*}$ & -1.77 \\
\hline Children & -0.028 & -0.57 & -0.043 & -0.69 & -0.005 & -0.10 & $-0.276^{* * *}$ & -2.67 \\
\hline Higher education & $0.204^{*}$ & 1.81 & 0.058 & 0.41 & -0.044 & -0.34 & 0.018 & 0.08 \\
\hline Investment & -0.058 & -0.49 & -0.069 & -0.46 & 0.021 & 0.15 & -0.352 & -1.45 \\
\hline BMI: underweight & -0.048 & -0.17 & -0.160 & -0.45 & $0.555^{*}$ & 1.74 & 0.120 & 0.25 \\
\hline BMI: overweight & $-0.196^{*}$ & -1.75 & 0.149 & 1.05 & 0.096 & 0.76 & -0.105 & -0.47 \\
\hline \multirow[t]{3}{*}{ Coefficients of correlations } & 1 & - & $0.125^{* *}$ & 2.07 & $0.179^{* * *}$ & 2.97 & 0.107 & 1.26 \\
\hline & & & 1 & - & 0.094 & 1.55 & $0.157^{*}$ & 1.78 \\
\hline & & & & & 1 & - & 0.008 & 0.08 \\
\hline
\end{tabular}

Log likelihood

$-1141.5$

Note: Maximum likelihood estimates from seemingly unrelated regressions comprising three continuous equations for physical characteristics, non-physical characteristics and undesirable characteristics and one Probit equation for refusing children. Significance levels are respectively $1 \%\left({ }^{* * *}\right), 5 \%\left(^{* *}\right)$ and $10 \%\left(^{*}\right)$. 
Table 3. Most frequently demanded and undesirable characteristics, by gender A. Men

\begin{tabular}{|c|c|c|c|c|c|}
\hline \multicolumn{2}{|c|}{ Physical characteristics sought } & \multicolumn{2}{|c|}{ Personal characteristics sought } & \multicolumn{2}{|c|}{ Undesirable characteristics } \\
\hline Pleasant & $47.9 \%$ & Gentle & $33.7 \%$ & Vulgar & $19.0 \%$ \\
\hline Femininity & $14.8 \%$ & Thoughtful & $12.3 \%$ & Smoker & $13.6 \%$ \\
\hline Thin & $12.3 \%$ & Kind & $12.0 \%$ & Unfaithful & $9.6 \%$ \\
\hline Charming & $9.9 \%$ & Frank & $11.1 \%$ & Liar & $5.7 \%$ \\
\hline Tall & $7.5 \%$ & Strong personality & $10.5 \%$ & Selfishness & $3.3 \%$ \\
\hline Dark-haired & $2.7 \%$ & Dynamic & $6.0 \%$ & Alcohol & $1.8 \%$ \\
\hline Elegant & $0.9 \%$ & Open & $5.7 \%$ & Violence & $0.6 \%$ \\
\hline \multicolumn{6}{|c|}{$\begin{array}{r}\text { B. Women } \\
\end{array}$} \\
\hline \multicolumn{2}{|c|}{ Physical characteristics sought } & \multicolumn{2}{|c|}{ Personal characteristics sought } & \multicolumn{2}{|c|}{ Undesirable characteristics } \\
\hline Pleasant & $45.0 \%$ & Thoughtful & $32.5 \%$ & Smoker & $22.5 \%$ \\
\hline Tall & $41.0 \%$ & Dynamic & $15.3 \%$ & Alcohol & $16.9 \%$ \\
\hline Charming & $16.9 \%$ & Frank & $14.1 \%$ & Selfishness & $12.4 \%$ \\
\hline Dark-haired & $10.0 \%$ & Gentle & $12.4 \%$ & Violence & $10.8 \%$ \\
\hline Thin & $8.0 \%$ & Kind & $12.0 \%$ & Liar & $9.2 \%$ \\
\hline Elegant & $5.2 \%$ & Open & $10.8 \%$ & Vulgar & $8.4 \%$ \\
\hline Femininity & $0.0 \%$ & Strong personality & $8.8 \%$ & Unfaithful & $7.6 \%$ \\
\hline
\end{tabular}


Table 4. Marginal effects from Probit models of the most desired and undesired characteristics in partner A. Physical characteristics sought

\begin{tabular}{|c|c|c|c|c|c|c|c|c|}
\hline \multirow{2}{*}{ Variables } & \multicolumn{4}{|c|}{ Men } & \multicolumn{4}{|c|}{ Women } \\
\hline & Pleasant & Femininity & Thin & Charming & Pleasant & Tall & Charming & Dark \\
\hline Age & $+0.1 \%$ & $+0.4 \%$ & $+0.4 \%$ & $-0.1 \%$ & $-0.2 \%$ & $+0.3 \%$ & $-0.1 \%$ & $-0.3 \%$ \\
\hline Children & $+7.6 \%$ & $-3.6 \%$ & $-2.5 \%$ & $-1.2 \%$ & $+3.6 \%$ & $-3.1 \%$ & $+3.6 \%$ & $-1.9 \%$ \\
\hline Higher education & $-11.1 \%{ }^{*}$ & $+8.1 \%{ }^{*}$ & $+7.0 \%^{*}$ & $+0.3 \%$ & $-4.8 \%$ & $+15.8 \%^{* *}$ & $+7.3 \%$ & $-6.9 \% *$ \\
\hline Investment & $+12.1 \%{ }^{*}$ & $-12.2 \%^{* * *}$ & $+0.0 \%$ & $-8.5 \%^{* *}$ & $-5.8 \%$ & $-5.4 \%$ & $-0.5 \%$ & $-6.6 \%$ \\
\hline BMI: underweight & & & & & $+7.5 \%$ & $-6.2 \%$ & $-11.0 \%$ & $+18.2 \%^{* *}$ \\
\hline BMI: overweight & $-2.0 \%$ & $-3.2 \%$ & $-6.8 \%{ }^{*}$ & $+1.0 \%$ & $+4.7 \%$ & $-18.7 \%^{* *}$ & $-13.8 \%^{* *}$ & $-3.7 \%$ \\
\hline Secondary mate market & $-12.4 \%$ & $+5.5 \%$ & $+7.9 \%$ & $-0.4 \%$ & $+7.0 \%$ & $-10.0 \%$ & $-1.7 \%$ & $-1.4 \%$ \\
\hline Predicted probability & $47.8 \%$ & $12.9 \%$ & $11.3 \%$ & $9.3 \%$ & $44.9 \%$ & $40.0 \%$ & $15.3 \%$ & $8.1 \%$ \\
\hline
\end{tabular}

B. Non-physical characteristics sought

\begin{tabular}{|c|c|c|c|c|c|c|c|c|}
\hline \multirow{2}{*}{ Variables } & \multicolumn{4}{|c|}{ Men } & \multicolumn{4}{|c|}{ Women } \\
\hline & Gentle & Thoughtful & Kind & Frank & Thoughtful & Dynamic & Frank & Gentle \\
\hline Age & $+0.2 \%$ & $+0.4 \%{ }^{*}$ & $+0.2 \%$ & $-0.5 \%{ }^{*}$ & $-0.4 \%$ & $-0.2 \%$ & $+0.0 \%$ & $-0.3 \%$ \\
\hline Children & $+7.2 \%{ }^{* *}$ & $-0.3 \%$ & $+7.2 \%^{* *}$ & $-1.3 \%$ & $+5.7 \%$ & $+2.0 \%$ & $+3.7 \%$ & $-3.5 \%$ \\
\hline Higher education & $-4.5 \%$ & $+2.9 \%$ & $-4.5 \%$ & $+4.1 \%$ & $+1.5 \%$ & $-3.3 \%$ & $-1.1 \%$ & $-7.6 \%{ }^{*}$ \\
\hline Investment & $+3.0 \%$ & $-2.2 \%$ & $+3.0 \%$ & $-1.3 \%$ & $-1.1 \%$ & $+0.9 \%$ & $+0.0 \%$ & $+1.3 \%$ \\
\hline BMI: underweight & & & & & $+9.5 \%$ & $+8.6 \%$ & $-7.5 \%$ & $-8.7 \%$ \\
\hline BMI: overweight & $+10.5 \%{ }^{* *}$ & $-1.8 \%$ & $+10.5 \%{ }^{* *}$ & $+2.4 \%$ & $-11.9 \%$ & $-10.1 \%{ }^{*}$ & $-2.8 \%$ & $+0.4 \%$ \\
\hline Secondary mate market & $-14.7 \%^{* *}$ & $+0.4 \%$ & $-14.7 \%^{* *}$ & $+15.8 \%{ }^{* * *}$ & $+3.3 \%$ & $-16.9 \%^{* *}$ & $-8.7 \%$ & $+1.1 \%$ \\
\hline Predicted probability & $10.6 \%$ & $11.9 \%$ & $10.6 \%$ & $10.1 \%$ & $32.1 \%$ & $12.8 \%$ & $13.6 \%$ & $10.9 \%$ \\
\hline \multicolumn{9}{|c|}{ C. Undesirable characteristics } \\
\hline \multirow{2}{*}{ Variables } & \multicolumn{4}{|c|}{ Men } & \multicolumn{4}{|c|}{ Women } \\
\hline & Vulgar & Smoker & Unfaithful & Liar & Smoker & Alcohol & Selfish & Violence \\
\hline Age & $-0.5 \%$ & $+0.1 \%$ & $-0.3 \%$ & $-0.1 \%$ & $+0.6 \%^{*}$ & $+0.2 \%$ & $-0.2 \%$ & $-0.5 \%{ }^{* *}$ \\
\hline Children & $-5.3 \%$ & $-4.1 \%$ & $+6.4 \%{ }^{* * *}$ & $+0.8 \%$ & $+0.2 \%$ & $-0.7 \%$ & $-1.1 \%$ & $-1.1 \%$ \\
\hline Higher education & $+1.6 \%$ & $+2.6 \%$ & $-0.8 \%$ & $-0.4 \%$ & $+2.7 \%$ & $-7.9 \%$ & $+5.9 \%$ & $-3.0 \%$ \\
\hline Investment & $+6.7 \%$ & $+4.2 \%$ & $+7.9 \%{ }^{* *}$ & $+5.7 \%{ }^{* *}$ & $+3.3 \%$ & $-3.6 \%$ & $+3.8 \%$ & $+4.1 \%$ \\
\hline BMI: underweight & & & & & $+3.8 \%$ & $-5.4 \%$ & $+15.3 \%{ }^{* *}$ & $+0.2 \%$ \\
\hline BMI: overweight & $+9.7 \%{ }^{*}$ & $+5.2 \%$ & $+3.7 \%$ & $+2.8 \%$ & $+4.5 \%$ & $+8.3 \%$ & $-5.7 \%$ & $+11.3 \%{ }^{*}$ \\
\hline Secondary mate market & $+6.5 \%$ & $-8.3 \%$ & $-1.5 \%$ & $+1.0 \%$ & $-7.1 \%$ & $10.9 \%$ & $+2.0 \%$ & $+4.5 \%$ \\
\hline Predicted probability & $18.2 \%$ & $11.9 \%$ & $7.8 \%$ & $5.0 \%$ & $22.0 \%$ & $15.0 \%$ & $11.3 \%$ & $9.7 \%$ \\
\hline
\end{tabular}

Note: Marginal effects from Probit models for the four characteristics which are the most frequently quoted respectively by men and women. Significance levels are respectively $1 \%\left(^{* * *}\right), 5 \%\left(^{* *}\right)$ and $10 \%\left(\left(^{*}\right)\right.$. 
Figure 1. Variety of traits sought or rejected by clients

A. Men

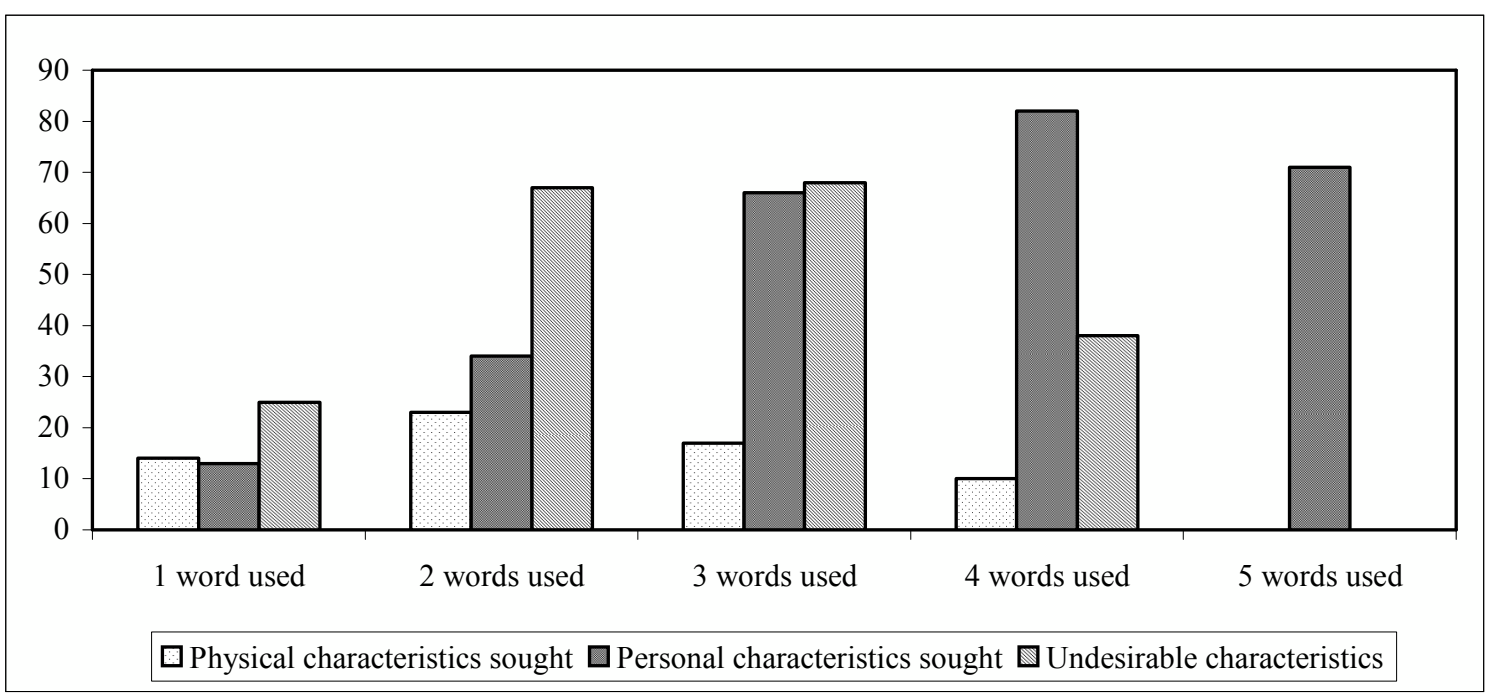

B. Women

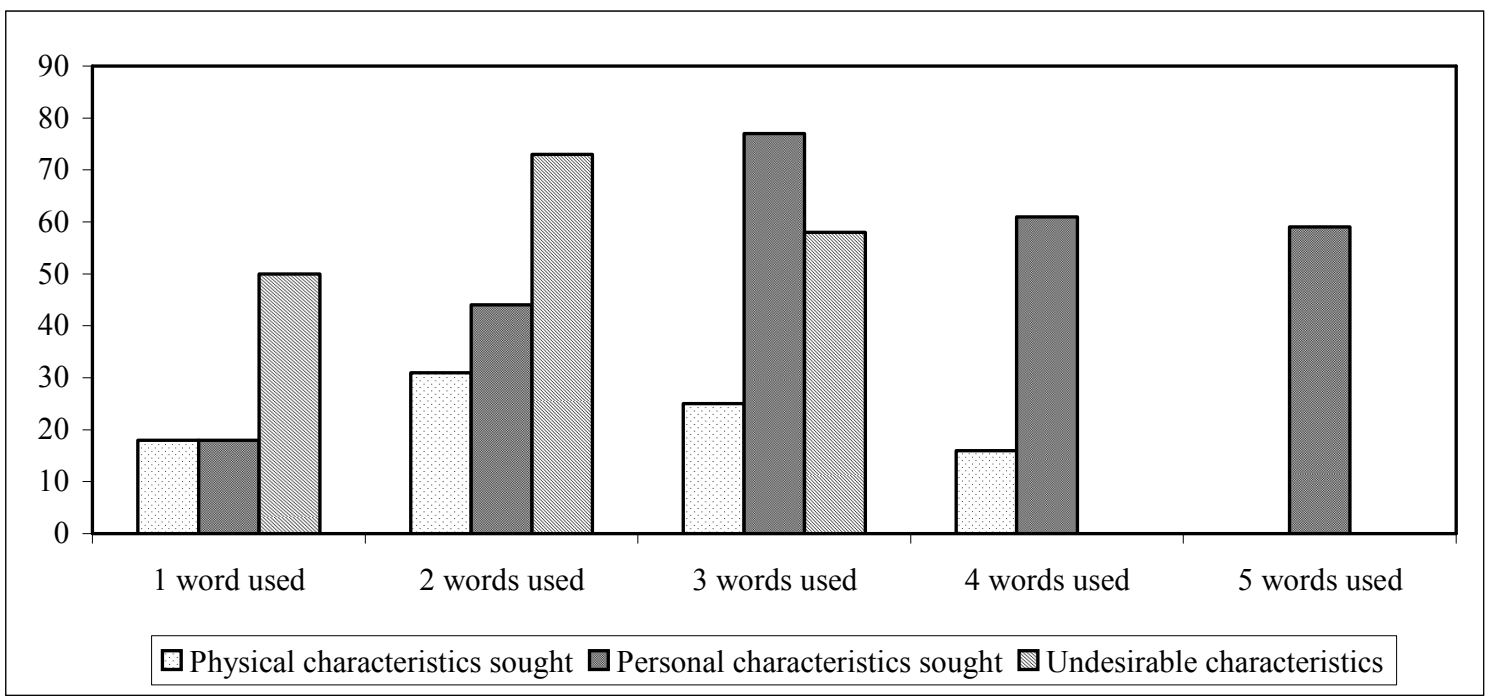

